Research Article

Fakhir Aziz Rasul Rozhbiany* and Shawnim Rashied Jalal

\title{
The Effectiveness of Reinforcement and Processing on Mechanical Properties, Wear Behavior and Damping Response of Aluminum Matrix Composites
}

https://doi.org/10.1515/htmp-2019-0039

Received Apr 06, 2019; accepted Jul 30, 2019

Abstract: Metal matrix composites are an essential product used in engineering materials. This product has wide applications in automotive, aerospace, and other uses because of their lower density, good specific strength, best machinability, and better mechanical properties compared to $\mathrm{Al} 6063$ alloy. In this paper, four different reinforced such as (MA), (MCA), (NFC) and (SA) with a constant rate of $5 \mathrm{wt} . \%$ for each reinforced element used and mixed with $\mathrm{Al} 6063$ alloy as a metal matrix composite by using modified two-step mechanical stirrer and having three blades at each step. Coated carbide tool insert was carrying out the turning process. Surface roughness measured after turning of every change in cutting speed. Average chip length and its shape style formation performed within cutting speeds of 10 and $90 \mathrm{~m} / \mathrm{min}$, which appears in different length and shapes. Mechanical properties, damping characteristics, and wear loss improved dramatically by adding all reinforced composites to the base $\mathrm{Al} 6063 \mathrm{al}$ loys. As the results of experiments, the surface roughness decreased by adding all four types of reinforcements. The mechanical properties, wear loss and damping characteristics improved by the constituents of all kinds of reinforcements and also by mixing of all types of constituents together. The effects of MA and NFC are more compared to MCA and SA for improving all conditions of experimental results. Microstructure observation produces compact grain boundaries with strong grains of metal matrix composites compared to $\mathrm{Al} 6063$ alloys.

Keywords: Surface roughness, Chip formation style, Mechanical properties, Metal matrix composites (MMCs)

\section{Nomenclature}

$\begin{array}{ll}\text { Al } & \text { aluminum } \\ \text { La } & \text { average chip length } \\ \text { MA } & \text { mortar ash } \\ \text { MCA } & \text { met coke ash } \\ \text { MMCs } & \text { metal matrix composites } \\ \text { NFC } & \text { nano fibrillated composite } \\ \text { Ra } & \text { average surface roughness } \\ \text { SA } & \text { straw ash } \\ \text { SEM } & \text { scanning electron microscope } \\ \text { SN } & \text { sample number } \\ \text { UTS } & \text { ultimate tensile strength } \\ \text { Vc } & \text { cutting speed } \\ \text { YTS } & \text { yield tensile strength }\end{array}$

\section{Introduction}

Stir casting is mostly used to produce the MMCs called as materials system which has two or more micro/macro with different composition. Some properties of MMCs have better performance, high accuracy with a higher rate of production. An application of MMCs includes automotive area involves industrial applications because they have best properties. Aluminum and its alloys are chosen as the excellent stiffness, good mechanical properties, and best corrosion resistance with lightweight. The homogeneous distributions of reinforcements in the matrix of processing MMCs are significant challenges of production, and it has a strong impact on the quality of properties and material [18].

Shawnim Rashied Jalal: Department of Mechanical \& Mechatronics Engineering, College of Engineering, Salahaddin UniversityErbil, Erbil, Kurdistan Regional Government (KRG), Iraq

\footnotetext{
^Corresponding Author: Fakhir Aziz Rasul Rozhbiany: Department of Mechanical \& Mechatronics Engineering, College of Engineering, Salahaddin University-Erbil, Erbil, Kurdistan Regional Government (KRG), Iraq; Email: fakhir.rozhbiany@gmail.com
}

(cc) $\mathbf{B Y}$

ə Open Access. (C) 2019 F. Aziz Rasul Rozhbiany and S. Rashied Jalal, published by De Gruyter. Creative Commons Attribution 4.0 License This work is licensed under the 
Solid and liquid states are two ways of manufacturing of aluminum metal matrix composites. The preferred method is the liquid state because of its simplicity and scalability. The provide advantage of metal matrix composites over monolithic metals such as steel and aluminum. Aluminum metal matrix composites have more characteristics such as better wear, fatigue, elastic properties, higher electric, and higher thermal conductivities. Composites give the right combination of two or more materials to get the best properties. Materials development has changed by shifting from monolithic to composite materials due to reduced weight, weight, quality, high performance, and low cost. Reinforced nanostructure has low thermal conductivity and better shock resistance. The design goal of composites is obtained by improved mechanical and functional properties [9-13].

\section{Literature review}

Prasad et al. [14] practically showed the extensive study on the damping behavior of elemental rice husk ash, fly ash, silicon carbide and graphite powder at three different frequencies of $0.1 \mathrm{~Hz}, 1 \mathrm{~Hz}$ and $10 \mathrm{~Hz}$ over various range of temperatures, the results show that rice husk ash exhibit low damping value among all the powders and the damping capacity of fly ash was found to decrease at 0.1 $\mathrm{Hz}$ and $1 \mathrm{~Hz}$, but for silicon carbide increase with temperature. Bodunrin et al. [15] developed many tested about agro wastes in MMCs include: bamboo leaf ash (BLA), rice husk ash (RHA), bagasse ash (BA), palm kernel shell ash (PKSA), maize stalk ash (MSA), corn cob ash (CCA), bean shell waste ash (BSWA) mentioned a few and the development of hybrid aluminum matrix composites (AMCs) with agro waste ash serving as complementing reinforcement, agro waste has improvement for most properties of AMCs with single reinforced AMCs. Double synthetic reinforcement hybrid composites compared the mechanical properties obtain with unreinforced alloy rather than the unique reinforced composite. Therefore further investigation should be carried out to determine how much the mechanical properties are improved when comparing the hybrid composites with double synthetic reinforcement to single reinforced composites.

Sood et al. [16] experimentally showed semi-solid metal processing carried out by mechanical stirring on the machinability studies of Al-20Si-0.5Mg-1.2Fe based alloy to determine the influence of cutting speed, feed rate and depth of cut by using the constant rate of beryllium and cadmium $0.03 \%$ as reinforced metal, the results show that the length of chip changed under different machining conditions, on the other hand, there is an improvement in the rate of surface roughness and cutting force. Hindi et al. [17] described ceramic material such as silicon carbide of 2, 4 and $6 \%$ as reinforcement are manufactured using conventional stir casting technique, the microstructure reveals better dispersion of reinforcement in the matrix, hardness and tensile strength of $6 \% \mathrm{SiC}$ be higher than $2 \& 4 \%$, but the ductility and the impact strength are improvements with 4\% SiC. Phanibhubshana et al. [18] analyzed practically the application of varied rate of hematite also known as ferrous oxide $\left(\mathrm{Fe}_{2} \mathrm{O}_{3}\right)$ as reinforcement mixing with $\mathrm{Al}$ 6061 alloy by stir casting technique, hematite added in different proportions 2, 4, 6 and 8, significant improvement in hardness and tensile strength observed with the increase of hematite rate and microstructural studies showed better bonding and dispersion of the $\mathrm{Fe}_{2} \mathrm{O}_{3}$ metal matrix composites.

Alaneme et al. [19] investigated the combination of groundnut shell ash (GSA) and silicon carbide (SiC) with different mixing ratio (10:0, 7.5:2.5, 5.0:5.0, 2.5:7.5 and 0:10) constituted 6 and $10 \%$ of the reinforcing phase with the matrix material of Al-Mg-Si produced via two-step stir casting technique, the percentage elongation improved marginally and was generally invariant to increasing GSA content while the fracture toughness increased with increasing GSA content, hardness and tensile strength increases with increasing weight percent of the reinforcing phase, but the strength and hardness dropped slightly with an increase in GSA content in the reinforcing phase. Haider et al. [20] showed the signs of the hard ceramics SiC and $\mathrm{Al}_{2} \mathrm{O}_{3}$ by stir casting route; the results indicated that the developed successfully, and there is an increase in the value of tensile strength, hardness and impact strength. Raju et al. [21] studied on the surface roughness of pure commercial $\mathrm{Al}$ and $\mathrm{Al}-15 \%$ coconut shell ash (CSA) composite by stir casting method, the results of machining parameters such as cutting speed, feed rate and depth of cut on surface roughness were analyzed and become improvement on surface roughness. This study attempt reveals different types of reinforcement components such as ceramics MA and NFC, synthetic MCA, and waste vegetable SA.

The mechanical properties, wear, damping, and machining test experiments of the new generation of metal matrix composites has been performed and compared to the base $\mathrm{Al} 6063$ alloys via stir casting process. The aim of this paper was used ceramic reinforced MA and NFC, which is used as new reinforcement and compared it with synthetic and further agro waste straw ash reinforcements MCA and SA respectively. The results show good agree- 
Table 1: Chemical compositions of Al 6063 alloy.

\begin{tabular}{ccccccccc}
\hline Elements & $\mathrm{Si}$ & $\mathrm{Mg}$ & $\mathrm{Fe}$ & $\mathrm{Sn}$ & $\mathrm{Ti}$ & $\mathrm{Mn}$ & $\mathrm{Cr}$ & $\mathrm{Al}$ \\
\hline Amount (wt.\%) & 0.44 & 0.40 & 0.17 & 0.03 & 0.03 & 0.01 & 0.01 & Balance \\
\hline
\end{tabular}

Table 2: Chemical compositions of MA.

\begin{tabular}{ccc}
\hline Elements & $\mathrm{Al}_{2} \mathrm{O}_{3}$ & $\mathrm{Fe}_{2} \mathrm{O}_{3}$ \\
\hline Amount (wt.\%) & 90 & 10 \\
\hline
\end{tabular}

Table 3: Chemical compositions of NFC.

\begin{tabular}{ccc}
\hline Elements & $\mathrm{SiO}_{2}$ & $\mathrm{Cr}_{2} \mathrm{O}_{3}$ \\
\hline Amount (wt.\%) & 70 & 30 \\
\hline
\end{tabular}
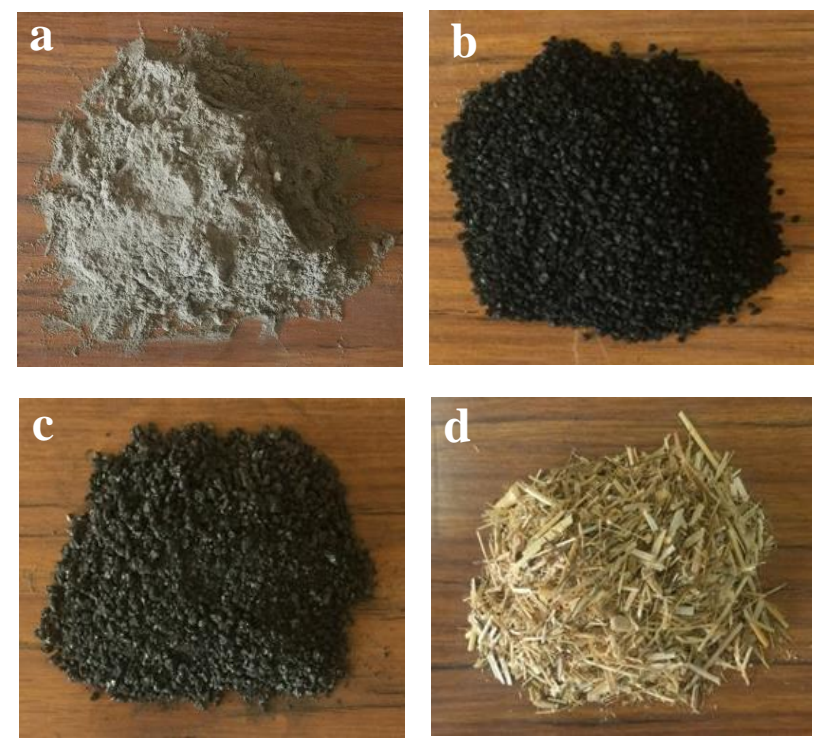

Figure 1: (a) MA, (b) NFC, (c) MCA and (d) SA.

ment and improvement in hardness, tensile strength, wear, and damping characteristics. Aluminum matrix composites are manufactured in this study have many applications in a wide range in mechanical components and invehicle parts such as pillars, bumper beam, and crush box because aluminum matrix composites are making the vehicles lighter, safer and more fuel-efficient. We use Aluminum matrix composites in this study because we have many reasons to define this type as appropriate composite; these reasons are (high hardness to density, excellent resistance to impact and wear rate and improve damping response). On the other hand, it can be recycling useless ceramics, synthetic, and agro wastes as reinforced materials.
Table 4: Chemical compositions of MCA.

\begin{tabular}{|c|c|c|c|}
\hline Elements & Fixed carbon & \multicolumn{2}{|c|}{ Volatile matter } \\
\hline Amount (wt.\%) & $72 \mathrm{Min}$ & & $4 \operatorname{Max}$ \\
\hline Elements & Ash & Moisture & Sulfur \\
\hline Amount (wt.\%) & $24 \operatorname{Max}$ & $2 \operatorname{Max}$ & 0.70 Max \\
\hline
\end{tabular}

Table 5: Chemical compositions of SA.

\begin{tabular}{ccccccc}
\hline Elements & $\mathrm{Cu}$ & $\mathrm{Ni}$ & $\mathrm{Mn}$ & $\mathrm{Co}$ & $\mathrm{Pb}$ & $\mathrm{Fe}$ \\
\hline $\mathrm{ppm}$ & 85.60 & 68.30 & 25.50 & 3.30 & 0.98 & 0.70 \\
\hline
\end{tabular}

\section{Selection of the material}

\subsection{Base metal}

In this research, the material matrix alloy is $\mathrm{Al} 6063$. The chemical compositions of Al 6063 alloy are shown in Table 1 .

\subsection{Reinforcement materials}

The selection of reinforcement material for aluminum is essential facts such as density, wettability, and thermal stability considered. In this study, two types of ceramics and one type of synthetic and also one type of waste vegetable materials are used as reinforced metals such as MA, NFC, MCA and SA as shown in Figure 1. Chemical compositions of all four types of reinforcement materials are tabulated in Tables 2, 3, 4, and 5.

\section{Experimentation setup and procedures}

\subsection{Fabrication of metal matrix composites}

Aluminum 6063 alloy ingots were used as the matrix material and reinforced particles required having $5 \mathrm{wt} . \%$ were evaluated using charge calculations. The reinforced particles were initially preheated at a temperature of $500^{\circ} \mathrm{C}$ by using an analogue electric furnace to help improve wetta- 
Table 6: Al 6063 alloy and their constituents.

\begin{tabular}{cc}
\hline SN & Sample detail compositions \\
\hline 1 & Al 6063 \\
2 & Al $6063+5$ wt. $\%$ MA \\
3 & Al $6063+5$ wt. $\%$ MCA \\
4 & Al $6063+5$ wt. $\%$ NFC \\
5 & Al $6063+5$ wt. $\%$ SA \\
6 & Al $6063+5$ wt. $\%$ MA +5 wt. $\%$ NFC + 5 wt. $\%$ MCA \\
& +5 wt. $\%$ SA \\
\hline
\end{tabular}

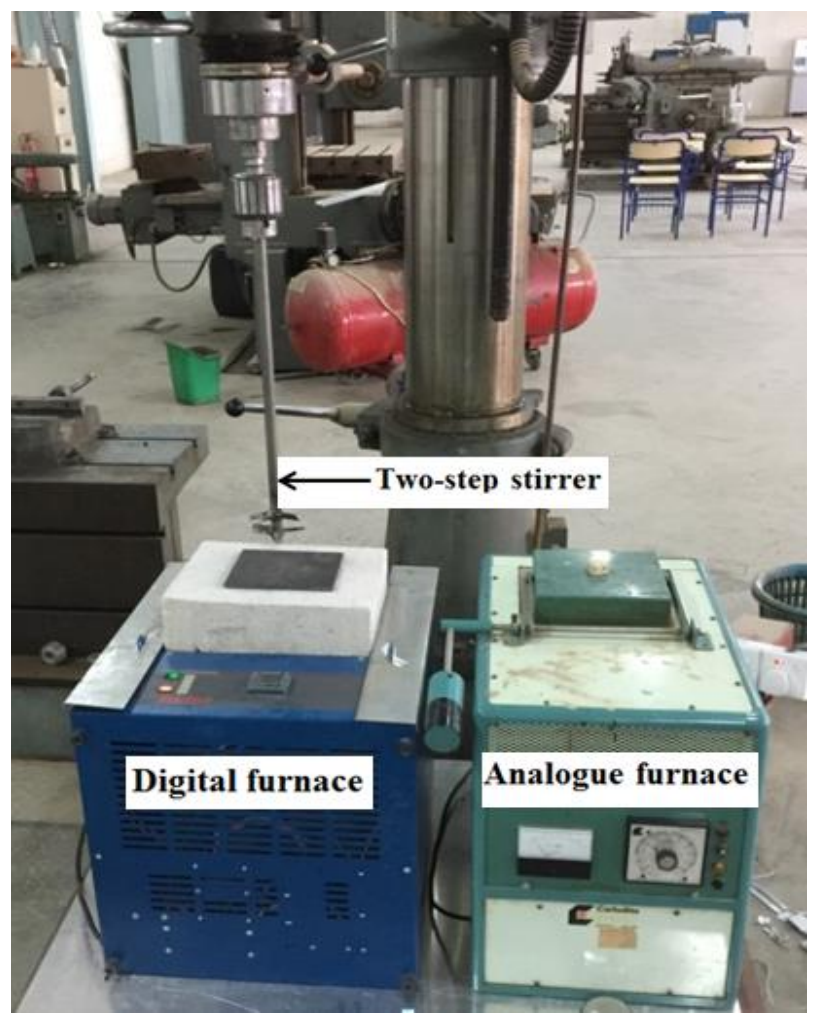

Figure 2: Experimental techniques.

bility with the Aluminum 6063 alloy for 30 minutes. The Aluminum 6063 ingots were charged into a digital electric furnace and heated to a temperature of $750 \pm 30^{\circ} \mathrm{C}$. The preheated reinforced particles were added at this temperature and stirring of the slurry was performed by using modified two-step mechanical stirrer and having three blades at each step. The stirring operation speed and time were performed $360 \mathrm{rpm}$ and 10 minutes respectively to help improve the distribution of the reinforced particles in the molten aluminum 6063 alloys. Finally, the molten composite slurry was poured into the steel mold to solidify. A schematic view of the stir casting set up shown in Figure 2. The constituent of Al 6063 alloy and its sample detail compositions shown in Table 6.

\subsection{Machinability conditions and their levels}

The machining experiments were carried out on a TAKISAWA SL-360 type center lathe machine using coated carbide inserts. The machining process was conducted on all ten samples of MMCs which were cast without using cooling or any lubricant (dry turning), and samples length of $35 \mathrm{~mm}$ was kept for each machining process during surface roughness measurements. The size of the workpiece is $28 \mathrm{~mm}$ (diameter) $220 \mathrm{~mm}$ (length). The average surface roughness $(\mathrm{Ra})$ measured by a TAYLOR-HOBSON (10) type instrument. A summary of the experimental conditions provided in Table 7.

The tool geometry with dimensions and cutting angles setup shown in Figure 3 and Table 8. The cutting angles and nose radius of the cutting tool are constant during all test samples.

\subsection{Chip formation style}

The chip formation style and its length that is involve as plastic deformation phenomena during the shear zone. Table 9 shows minimum, maximum, and average chip length.

\subsection{Surface roughness methodology}

A TAYLOR-HOBSON (10) type instrument was used and shown in Figure 4. It consists of a probe surface roughness calculating device connected to it. This device has two ways of reading the surface roughness, first is reading the average surface roughness Ra directly from the gauge, and the second is drawing the surface texture profile. The range of the device is reading from $(0.01 \mu \mathrm{m}$ to $5 \mu \mathrm{m})$, and the range of drawing the profile is from $(0.04 \mu \mathrm{m}$ to $60 \mu \mathrm{m})$. Table 10 showed the average surface roughness experimentally during five different cutting speeds.

\subsection{Mechanical properties and damping measurement}

Mechanical properties tests were carried out at room temperature by using TERCO MT 3037 Universal Testing Machine with standard dimensions of specimen for tensile test. The hardness and impact strength of the samples for all conditions were measured using the AVK Hardness Testing Machine and WP400 Pendulum Impact Instrument, re- 
Table 7: Experimental conditions summary.

\begin{tabular}{cc}
\hline Workpiece & Bar size: diameter $28 \mathrm{~mm}$ length $220 \mathrm{~mm}$ Machining length $=35 \mathrm{~mm}$ \\
Lathe used & TAKISAWA SL- 360 type center \\
Insert used & Coated carbide insert cutting tool, tool nose radius $=0.8 \mathrm{~mm}$ \\
Cutting speed $(\mathrm{m} / \mathrm{min})$ & $10,23,37,60$, and 90 \\
Feed rate $(\mathrm{mm} / \mathrm{rev})$ & 0.2 \\
Depth of cut $(\mathrm{mm})$ & 0.5 \\
Tool overhang $(\mathrm{mm})$ & 20 \\
Measuring instrument & A TAYLOR-HOBSON (10) type \\
Workpiece overhang $(\mathrm{mm})$ & 45 \\
Cutting condition & Dry turning (without using cooling or any lubricant) \\
\hline
\end{tabular}

Table 8: Cutting angles setup.

\begin{tabular}{cc}
\hline Cutting angles description & Degree \\
\hline Relief angle $(\alpha)$ & $7^{\circ}$ \\
Cutting edge angle $(\beta)$ & $67^{\circ}$ \\
Rake angle $(Y)$ & $16^{\circ}$ \\
End cutting edge angle $\left(\varphi_{e}\right)$ & $14^{\circ}$ \\
Side cutting edge angle $\left(\varphi_{s}\right)$ & $14^{\circ}$ \\
Insert included angle $(\epsilon)$ & $90^{\circ}$ \\
\hline
\end{tabular}
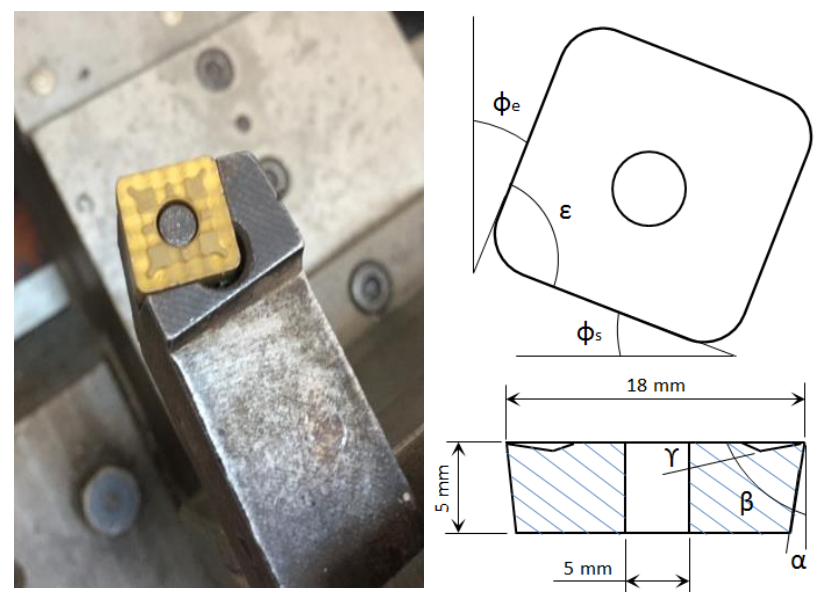

Figure 3: Tool geometry and dimensions.

spectively. The standard measurements for the tensile and impact test samples were ASTM A370 and ASTM E23, respectively. The results of Vickers Hardness Number, Impact Strength, Tensile Stresses, Elongation, and Peak Acceleration, as shown in Table 11.

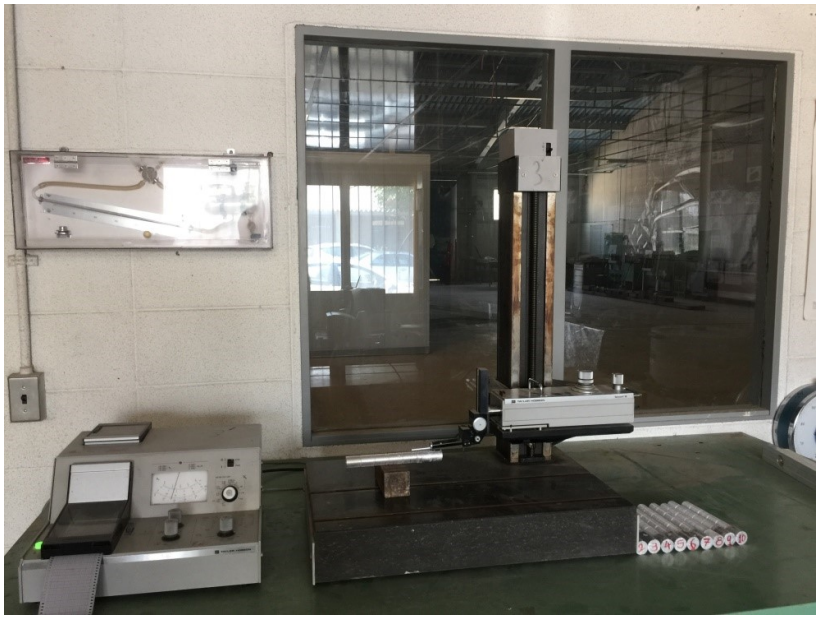

Figure 4: A TYLOR-HOBSON (10) surface roughness device.

\section{Results and discussion}

\subsection{The outcome of average surface roughness}

The outcome of average surface roughness has been employed to optimize the turning parameters for selecting the best type and amount of reinforcement material. The optimum values of average surface roughness within the different cutting speed and sample detail composition are showed entirely in Figure 5. The experimental design and the results are tabulated in Tables 9, 10, and 11. The average surface roughness was measured for all experiments. The effects of the input parameters such as cutting speeds $(10,23,37,60$, and $90 \mathrm{~m} / \mathrm{min})$ on the average surface roughness are showed in Table 10. Figure 5 shows the effect of cutting speed on average surface roughness within different sample detail composition.

It's seen from these values that the average surface roughness $\mathrm{Ra}$ is decreased with increasing particles vol- 
Table 9: The measured length of chip shape style.

\begin{tabular}{ccccccc}
\hline SN & \multicolumn{5}{c}{$\mathrm{Vc}=10 \mathrm{~m} / \mathrm{min}$} & \multicolumn{3}{c}{$\mathrm{Vc}=90 \mathrm{~m} / \mathrm{min}$} \\
\cline { 2 - 7 } & $\mathrm{L}_{\min }(\mathrm{mm})$ & $\mathrm{L}_{\max }(\mathrm{mm})$ & $\mathrm{L}_{a}(\mathrm{~mm})$ & $\mathrm{L}_{\min }(\mathrm{mm})$ & $\mathrm{L}_{\max }(\mathrm{mm})$ & $\mathrm{L}_{a}(\mathrm{~mm})$ \\
\hline 1 & 4 & 12 & 8 & 19 & 53 & 36 \\
2 & 3 & 7 & 5 & 29 & 115 & 72 \\
3 & 5 & 10 & 7.5 & 27 & 71 & 49 \\
4 & 11 & 45 & 28 & 26 & 107 & 66 \\
5 & 4 & 10 & 7 & 23 & 85 & 54 \\
6 & 4 & 9 & 6.5 & 7 & 17 & 12 \\
\hline
\end{tabular}

Table 10: Experiments of average surface roughness.

\begin{tabular}{|c|c|c|c|c|c|c|c|c|c|c|c|c|}
\hline \multirow[t]{2}{*}{ SN } & \multicolumn{6}{|c|}{$\mathrm{Vc}=10 \mathrm{~m} / \mathrm{min}$} & \multicolumn{6}{|c|}{$\mathrm{Vc}=23 \mathrm{~m} / \mathrm{min}$} \\
\hline & \multicolumn{2}{|l|}{$\mathrm{R}_{1}(\mu \mathrm{m})$} & $R_{2}(\mu \mathrm{m})$ & \multicolumn{2}{|l|}{$R_{3}(\mu \mathrm{m})$} & $\mathrm{R}_{a}(\mu \mathrm{m})$ & \multicolumn{2}{|l|}{$R_{1}(\mu \mathrm{m})$} & $\mathrm{R}_{2}(\mu \mathrm{m})$ & \multicolumn{2}{|l|}{$R_{3}(\mu \mathrm{m})$} & $\mathrm{R}_{a}(\mu \mathrm{m})$ \\
\hline 1 & 4.989 & & 4.852 & 4.877 & & 4.906 & 4.461 & & 4.307 & 4.411 & & 4.393 \\
\hline 2 & 4.759 & & 4.523 & 4.643 & & 4.641 & 3.826 & & 3.673 & 3.850 & & 3.783 \\
\hline 3 & 4.319 & & 4.175 & 4.343 & & 4.279 & 3.173 & & 3.529 & 3.414 & & 3.372 \\
\hline 4 & 4.425 & & 4.301 & 4.252 & & 4.326 & 3.384 & & 3.461 & 3.454 & & 3.433 \\
\hline 5 & 4.679 & & 4.804 & 4.719 & & 4.734 & 3.847 & & 3.926 & 4.143 & & 3.972 \\
\hline 6 & 4.480 & & 4.393 & 4.288 & & 4.387 & 3.372 & & 3.548 & 3.541 & & 3.457 \\
\hline \multirow[t]{2}{*}{ SN } & \multicolumn{4}{|c|}{$\mathrm{Vc}=37 \mathrm{~m} / \mathrm{min}$} & \multicolumn{4}{|c|}{$\mathrm{Vc}=60 \mathrm{~m} / \mathrm{min}$} & \multicolumn{4}{|c|}{$\mathrm{Vc}=90 \mathrm{~m} / \mathrm{min}$} \\
\hline & $\begin{array}{c}\mathrm{R}_{1} \\
(\mu \mathrm{m})\end{array}$ & $\begin{array}{c}\mathrm{R}_{2} \\
(\mu \mathrm{m})\end{array}$ & $\begin{array}{c}R_{3} \\
(\mu \mathrm{m})\end{array}$ & $\begin{array}{c}\mathrm{R}_{a} \\
(\mu \mathrm{m})\end{array}$ & $\begin{array}{c}R_{1} \\
(\mu \mathrm{m})\end{array}$ & $\begin{array}{c}R_{2} \\
(\mu \mathrm{m})\end{array}$ & $\begin{array}{c}R_{3} \\
(\mu \mathrm{m})\end{array}$ & $\begin{array}{c}\mathrm{R}_{a} \\
(\mu \mathrm{m})\end{array}$ & $\begin{array}{c}R_{1} \\
(\mu \mathrm{m})\end{array}$ & $\begin{array}{c}R_{2} \\
(\mu \mathrm{m})\end{array}$ & $\begin{array}{c}R_{3} \\
(\mu \mathrm{m})\end{array}$ & $\begin{array}{c}\mathrm{R}_{a} \\
(\mu \mathrm{m})\end{array}$ \\
\hline 1 & 3.637 & 3.483 & 3.500 & 3.540 & 3.106 & 2.947 & 2.692 & 2.915 & 2.277 & 1.950 & 2.208 & 2.145 \\
\hline 2 & 3.157 & 3.147 & 3.026 & 3.110 & 2.547 & 2.712 & 2.550 & 2.603 & 1.844 & 1.706 & 1.610 & 1.720 \\
\hline 3 & 2.583 & 2.496 & 2.490 & 2.523 & 2.307 & 2.290 & 2.177 & 2.258 & 1.440 & 1.306 & 1.400 & 1.382 \\
\hline 4 & 2.386 & 2.542 & 2.563 & 2.497 & 2.406 & 2.182 & 2.012 & 2.200 & 1.330 & 1.209 & 1.121 & 1.220 \\
\hline 5 & 3.085 & 3.192 & 3.092 & 3.123 & 2.710 & 2.631 & 2.576 & 2.639 & 1.804 & 1.732 & 1.708 & 1.748 \\
\hline 6 & 2.616 & 2.750 & 2.722 & 2.696 & 2.380 & 2.504 & 2.403 & 2.429 & 1.486 & 1.545 & 1.547 & 1.526 \\
\hline
\end{tabular}

Table 11: Observation of mechanical properties and peak acceleration of Al 6063 and their constituents.

\begin{tabular}{ccccccc}
\hline SN & $\begin{array}{c}\text { Vickers hardness } \\
\left(\mathrm{kg} / \mathrm{mm}^{2}\right)\end{array}$ & $\begin{array}{c}\text { Impact strength } \\
(\mathrm{J})\end{array}$ & UTS (MPa) & YTS (MPa) & Elongation (\%) & $\begin{array}{c}\text { Peak acceleration } \\
\left(\mathrm{m} / \mathrm{s}^{2}\right)\end{array}$ \\
\hline 1 & 50.36 & 7.32 & 130 & 95 & 23 & 136 \\
2 & 62.63 & 12.35 & 166 & 113 & 12 & 80 \\
3 & 53.47 & 9.78 & 153 & 103 & 14 & 95 \\
4 & 56.11 & 9.24 & 137 & 107 & 16 & 86 \\
5 & 54.69 & 12.10 & 169 & 119 & 13 & 113 \\
6 & 54.44 & 11.05 & 179 & 125 & 9 & 108 \\
\hline
\end{tabular}

ume fraction. It should be noted from the results of average surface roughness, that the NFC has reduced Ra dramatically for all cutting speeds due to its small and good bonding of structures $\mathrm{SiO}_{2}$ and $\mathrm{Cr}_{2} \mathrm{O}_{3}$. Followed by MCA it ranked the second one to improve $\mathrm{Ra}$, but the MA and SA have less effect on Ra compared to NFC and MCA due to its structure and grain size of MA and SA. From the results are shown in Table 10, the maximum and minimum values of Ra are $(4.906 \mu \mathrm{m}$ and $1.220 \mu \mathrm{m})$ at $10 \mathrm{~m} / \mathrm{min}$ and $90 \mathrm{~m} / \mathrm{min}$ respectively. The maximum different improvement values of Ra are (0.627, 1.021, 1.043, 0.715, and 0.925), so the best improvement of Ra is at cutting speed of $37 \mathrm{~m} / \mathrm{min}$. 


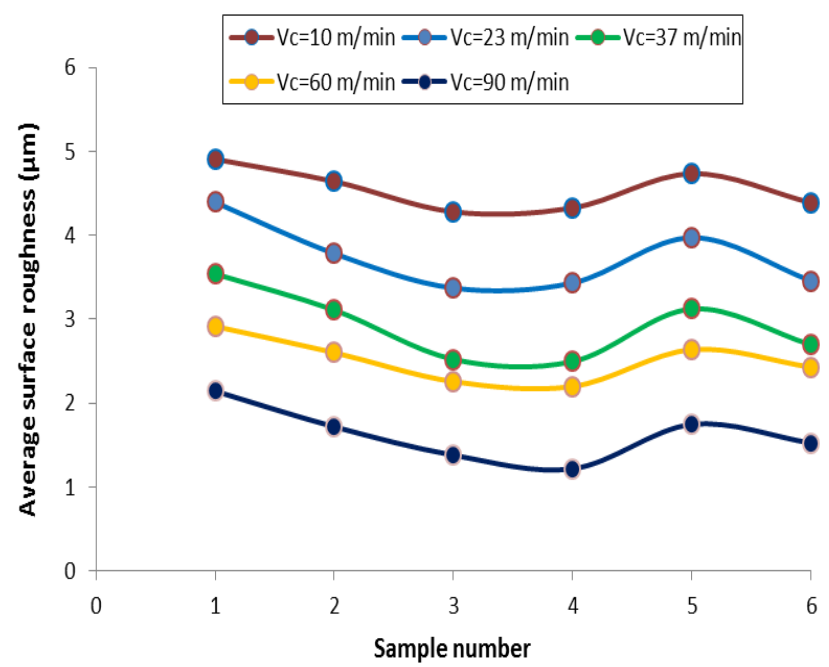

Figure 5: Effect of cutting speed on average surface roughness within different sample detail compositions.
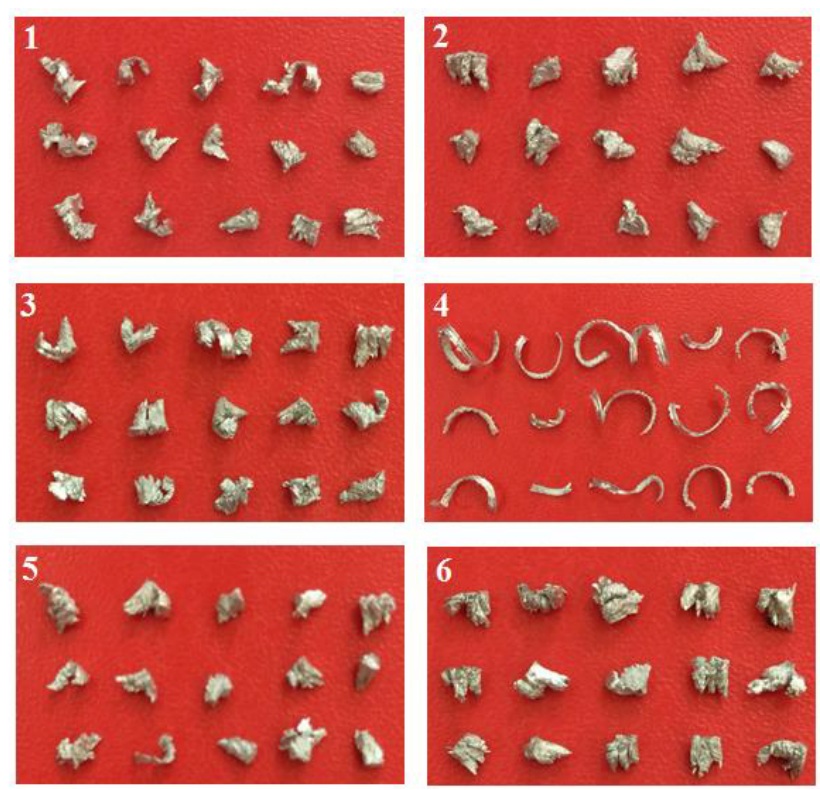

Figure 6: Chip formation style shape for all samples during cutting speed of $10 \mathrm{~m} / \mathrm{min}$.

\subsection{Influence of cutting speed on-chip shape formation length}

In this study, the chip shape formation and its length were studied concerning two different cutting speeds within constant of feed rate and depth of cut. Average chip length has been reported, as shown in Figure 8. The spring, semicircle, and helical shapes of the chip also are shown in Figures 6 and 7.

Type, length, and the shape of the chip depending directly on the physical and mechanical properties of
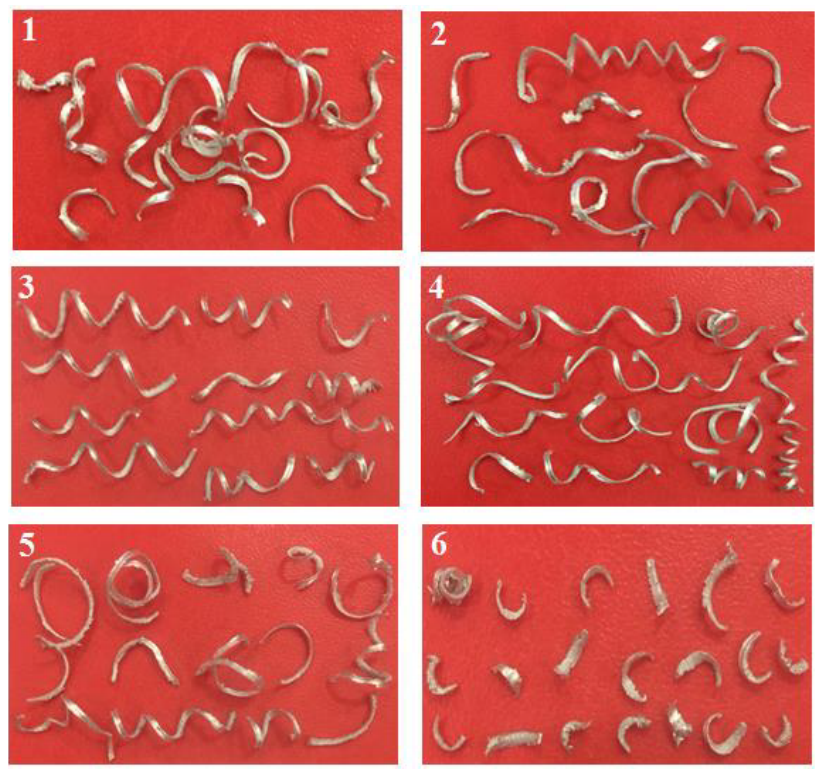

Figure 7: Chip formation style shape for all samples during cutting speed of $90 \mathrm{~m} / \mathrm{min}$.

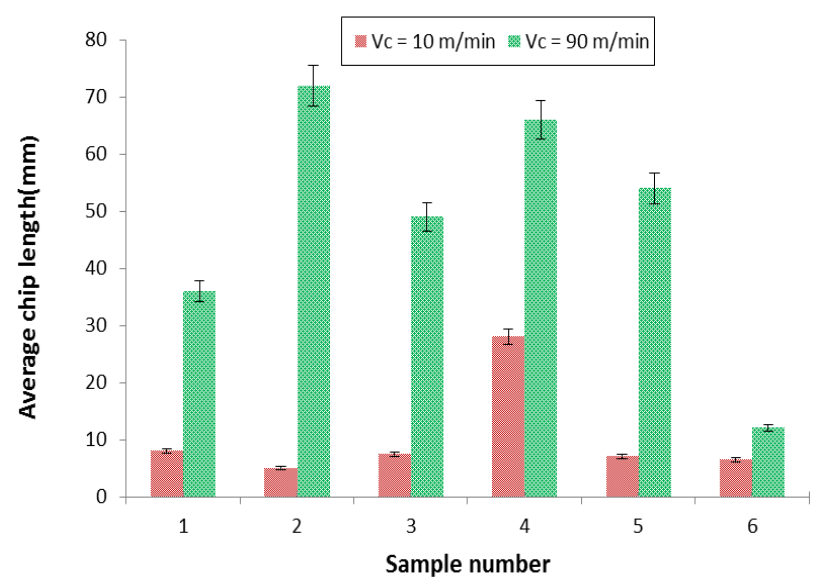

Figure 8: Effect of cutting speed on average chip length within different sample detail compositions.

machined material, such as heat generation, hardness, strength, chemical composition, and microstructure, also some cutting factors, such as cutting speed, when it increased, the chip becomes relatively ductility. Thus, more cutting speed increases; changing chips to the segmented microscopically. However, in a macroscopic state, the chips are increasingly in continuous form; this is probably due to their ductility. Also cutting force is necessary to machining is decreased when machining is carried out with higher cutting speed. Increasing the feed rates cause to increase the cutting forces. All the heat sources produced high temperature at the chip-tool interface, which substantially influences the chip formation mode. As mentioned 
above the effect and the interaction of the cutting condition on the cutting forces have been very complex [22].

The planned experiment was also developed for the influence of cutting speeds on average chip style length La. Table 9 showed La during cutting speeds of 10 and $90 \mathrm{~m} / \mathrm{min}$ for all sample numbers. Figure 8 observed due to the presence of reinforced particle metal proceeded, it found that $\mathrm{La}$ is maximum values when adding MA as in sample 2, because MA contains both aluminum and iron oxides, these two materials have high resistance and withstand to high cutting speed temperature between tool insert and workpiece, and it hindrance the separate of chip, so, for this reason, MA make more extended chip compared to other reinforced metals. NFC, MCA, and SA are medium average chip length La at high cutting speed compared to MA, but sample 6 is not perfect for high cutting speed because all types of reinforcement together damage the chips and decrease the length of it. Figure 8 also showed La at a low cutting speed of $10 \mathrm{~m} / \mathrm{min}$. NFC becomes the first best one for average chip length is followed by all other reinforcements due to low cutting speed and low cutting temperature, but MA is not perfect for high and low cutting speeds cutting. Figures 6 and 7 showed chip formation style shape during cutting speeds of 10 and $90 \mathrm{~m} / \mathrm{min}$, respectively; the Figures showed three forms of chips as known as spring, semi-circle, and helical. The spring shape known as continuous chip and the others were semi-circle and helical known as discontinuous chip. It found from Figures 6 and 7; reinforced metals can change the chip-style from discontinuous chip to continuous chip but in limited quality and quantity of reinforced metals. All of the results of the bar charts are taking into consideration the statistical with a 5 percentages validation error bar. This error bar shows and then communicate between real and a few errors during experimental results.

\subsection{Analysis of mechanical properties}

Table 11 shows that mechanical properties of pure Al alloy and composites produced by stir casting; all these properties increased by adding additives compared to unreinforced alloy.

The most considerable increased in mechanical properties found in sample 6 , the presence of all reinforcement together in the microstructure could impede the movement of dislocation since ceramic particles are stronger than the matrix in which they embedded, also have a solid lubricating effect due to the similar hexagonal closed packed structure. Using MCA as a reinforcement material sample 3 in $\mathrm{Al}$ alloy reduces tensile strength and hardness of the composites due to the segregation and particle clustering of MCA in the Al matrix when compared it with other reinforcements. Figure 9 shows the typical stress-strain curves of Al 6063, MA, NFC, MCA, and SA with constant rate contents of 5 wt. $\%$ as in Table 6 . Figure 9 shows the performance improvement of ultimate tensile stress. For the Al matrix, the elongation increases with a low rate of mechanical properties. For composites, the value of the tensile strength increase due to mixing additive metals such as ceramics, synthetic and waste vegetable, also increase due to a better distribution of microstructure by stirring method and less containing of porosities and inclusions inside the grain structure.

Several experiments of mechanical properties such as hardness, impact, elongation, yield, and ultimate tensile strength are carried out to get the best optimize results of mixing process by stir casting route. Figures 10, 11, 12, and 13 show the variation of mechanical properties of $\mathrm{Al}$ 6063 alloy and its composites.

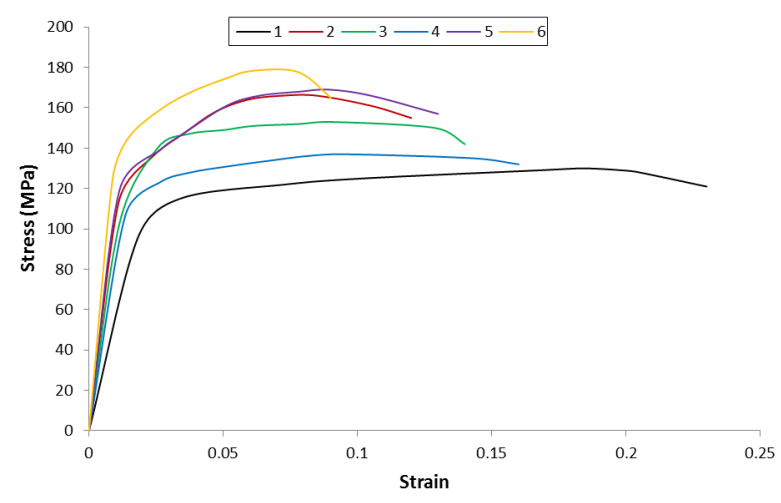

Figure 9: Typical stress-strain curves of all test samples.

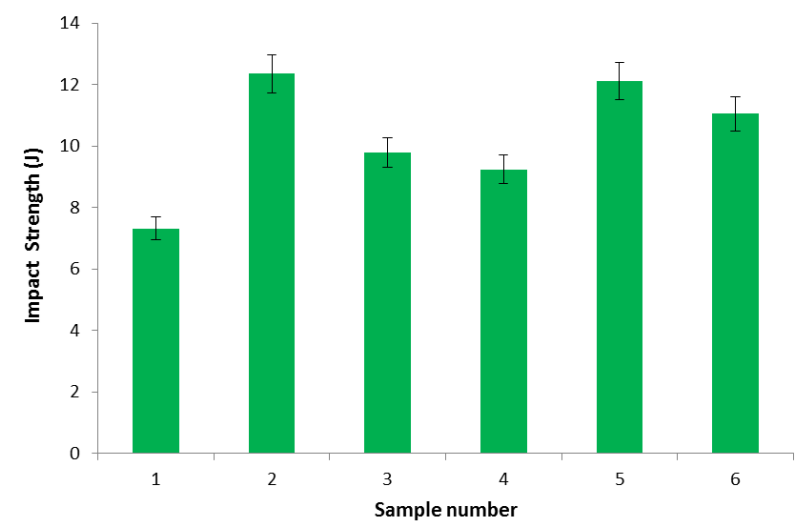

Figure 10: Vickers hardness for all composites. 


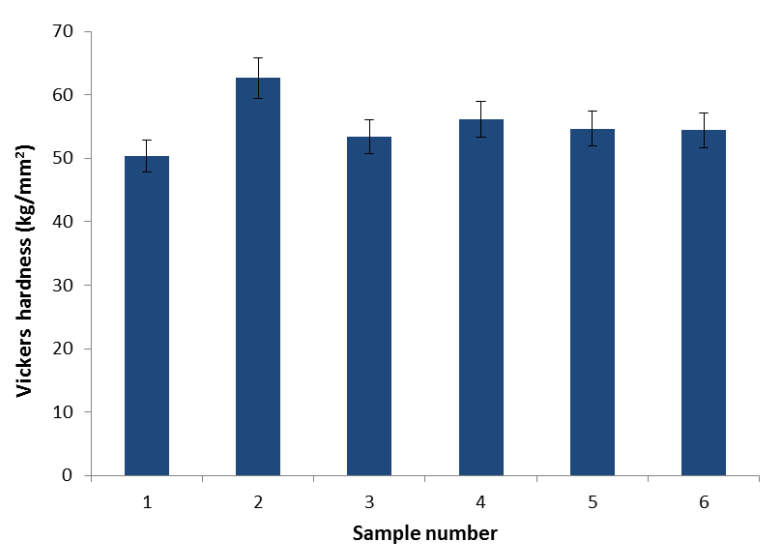

Figure 11: Impact strength for all composites.

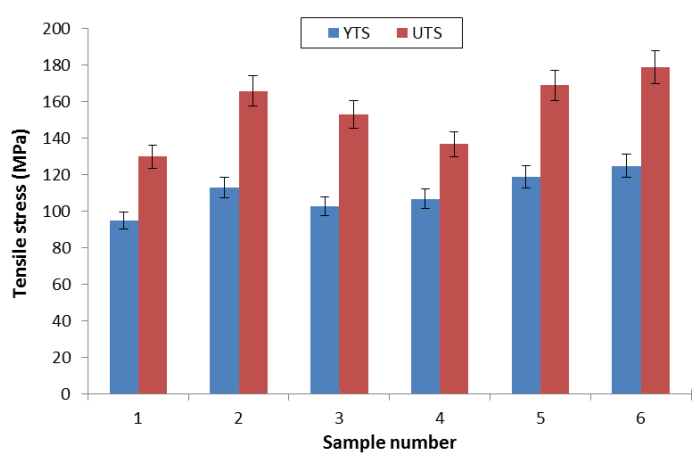

Figure 12: Variation of yield and ultimate tensile strength for all composites.

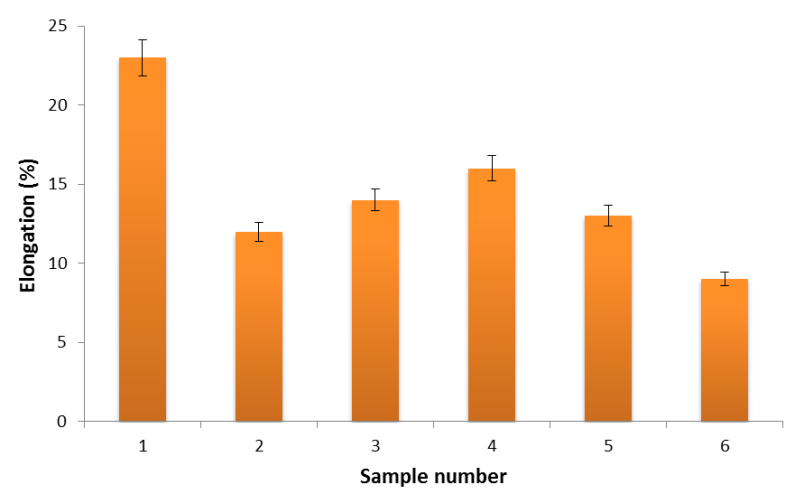

Figure 13: Variation of elongation for all composites.

The mechanical properties in terms of impact, hardness, tensile strength, and elongation are tabulated in Table 11. Figure 10 shows the behavior of vickers hardness of metal matrix composites and $\mathrm{Al} 6063$ alloy. The results show a functional difference between the base metal Al 6063 alloy and $\mathrm{Al} 6063$ metal matrix composites, which presents that the additional metals have a good change in the results. MA has great effect of increasing the hardness followed by NFC, which also has a good change for increasing the hardness because MA and NFC were ceramic metal and have a high melting temperature. The result of hardness due to adding MA was $62.63 \mathrm{~kg} / \mathrm{mm}^{2}$ as in sample 2 , but the unfortunate result of hardness was due to adding the synthetic metal MCA as in sample 3 is $53.47 \mathrm{~kg} / \mathrm{mm}^{2}$.

Figure 11 illustrates the impact of the strength of all composites. The results of impact strength were different compared to the results of hardness, samples 2, 5 and 6 have more effect for increased impact strength, here you would prefer when mixing all elements of reinforced metals such as in sample 6. From the results, we can show that the mortar ceramic and vegetable have the primary role in increasing the impact strength.

The variation of yield and ultimate tensile strength for all composites plotted in Figure 12. Sample 6 had maximum values of YTS and UTS compared to other samples, and the results were 125 and $179 \mathrm{MPa}$ respectively, this increase due to strong, compact bonding of grains and proper grain boundary distribution of this type of composite material as indicated in microstructure evaluation in Figure 16(6). All kinds of reinforced metal are using in this research have a good change in the results of YTS and UTS compared to base metal $\mathrm{Al} 6063$ alloy. The second effect is SA, which increases YTS and UTS as in sample 5, this phenomenon showed that the vegetable reinforced metal has great benefit for increasing the properties of $\mathrm{Al} 6063$ alloy.

Figure 13 shows the variation of elongation for all composites; the elongation decreases approximately in the range of 30 to $60 \%$ compared with that of $\mathrm{Al} 6063$ alloy under optimum constant values of reinforced metals. The small decrease of elongation was by NFC as in sample 4, but in general, the reduction of elongation achieved when all four types of reinforced metal mixing with a constant amount as in sample 6 . The results above showed that the ceramic, synthetic, and waste vegetable reinforced metals have a perfect effect of changing the mechanical properties of $\mathrm{Al} 6063$ alloy.

Sample 6 showed higher yield strength and lower elongation compared with sample 5, as in Table 11. Sample 6 contains 20\% reinforcement, while sample 5 includes 5\% reinforcement, as shown in Table 6. Due to the presence of the dispersed reinforcement particles in the Al alloy dislocation loops form when dislocations pass the particles (orowan mechanism). The dislocation might lead to making local stress and also increase the strength of the composites. The above process increased with increasing reinforcement percent. Moreover, elongation percent of composites increases with decreasing weight percent of reinforcement. The increment of ductility can be attributed to 


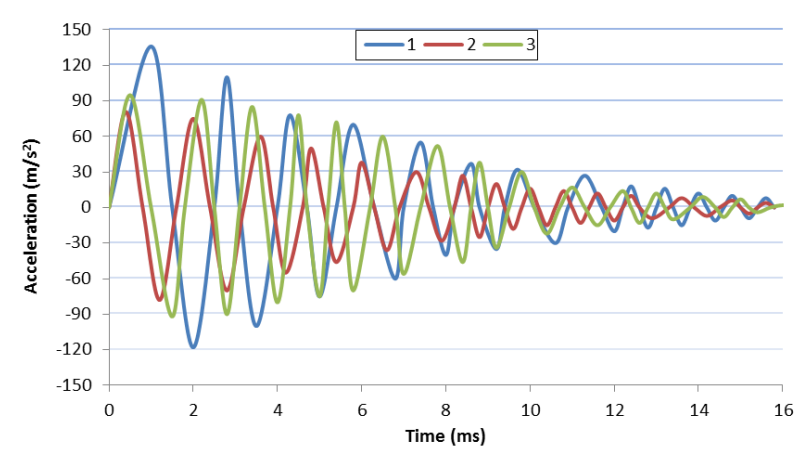

(a)

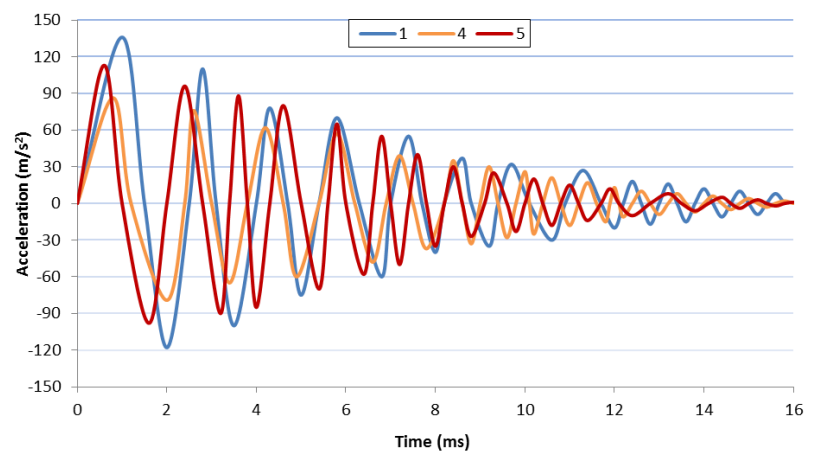

(b)

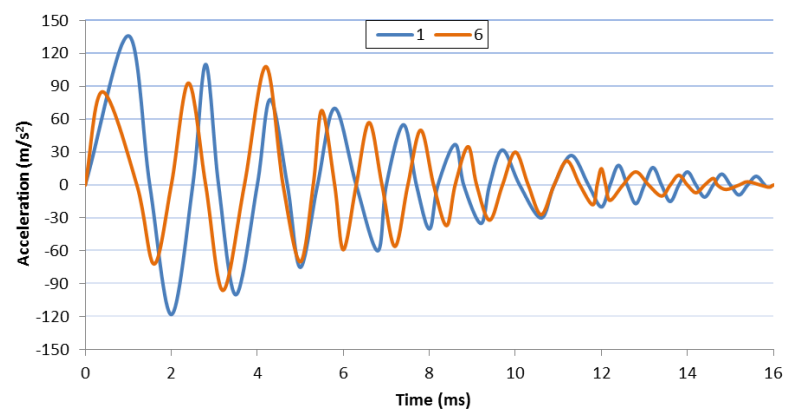

(c)

Figure 14: Variation of acceleration with the time for free vibration based composites containing: (a) (1) Al 6063; (2) Al $6063+5 \% \mathrm{MA}$; (3) Al $6063+5 \%$ MCA; (b) (1) Al 6063; (4) Al 6063 + 5\% NFC; (5) Al $6063+5 \%$ SA; (c) (1) Al 6063; (6) Al $6063+5 \%$ MA + 5\% MCA + 5\% $\mathrm{NFC}+5 \% \mathrm{SA}$.

the effect of an increase in grain boundary area due to grain reinforcement, the strong multi-directional thermal stress at the $\mathrm{Al} /$ reinforcement interface, and the effective transfer of applied tensile load to the uniformly distributed enormous number of well-bonded strong reinforcement particulates [23].

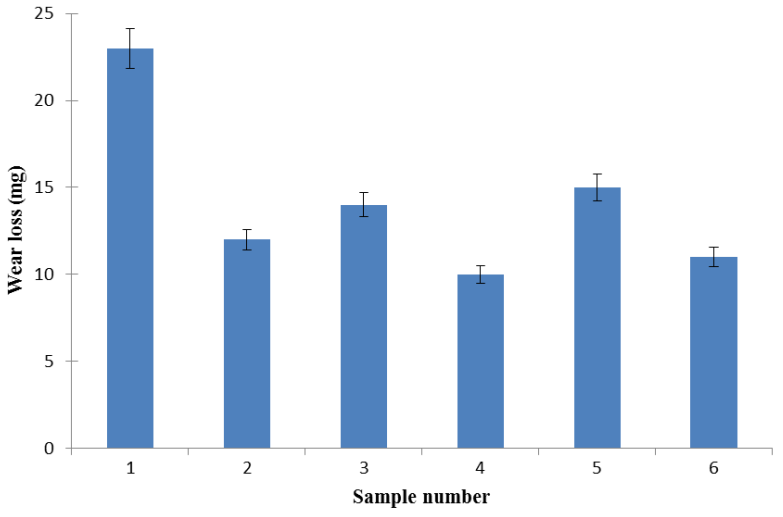

Figure 15: Variation of wear loss for all composites.

\subsection{Damping characteristics test}

Every material has different damping characteristics due to its structure. The capacity of damping considers the ability of a material to withstand mechanical energy during the application of vibration. The experiments performed at room temperature are using Brüel \& Kjaer Controller Modules Type 7539 5-channels Pulse Data Acquisition software with a cell sensor Accelerometer Type 4507 B 30515 set-up on the face on each sample to transfer the damping from cell sensor to computer via interface instrument to read and plot acceleration and amplitude concerning time.

The variations of the acceleration with the time for free vibration are based composites presented in Figure 14. It observed from Figure 14a to Figure 14c. It can be noted that by the addition of ceramic reinforcements such as MA and NFC which improved the damping characteristics strongly compared to another reinforcement such as synthetic and waste vegetable reinforcements especially in sample 2 , it recorded the minimum value of peak acceleration 80.8 $\mathrm{m} / \mathrm{s}^{2}$. The peak acceleration is the maximum current due to load determines, the acceleration level, which can be obtained peak accelerates. It's also related to a functional frequency, for example, at low frequency, the significant of the peak acceleration level of the results will decrease due to the displacement limit of the moving element. Resonances in the moving element will set the upper-frequency limit. This value indicates a good factor compared to $\mathrm{Al}$ 6063 alloy, and it recorded $136 \mathrm{~m} / \mathrm{s}^{2}$ of peak acceleration as in Figure 14a. Figure 14 mentioned damping characteristics curve of acceleration and time for all types of reinforcements such as MA, MCA, NFC, and SA with Al 6063 alloy. Figure 14a shows two different types of ceramic and synthetic reinforcements with the $\mathrm{Al} 6063$ alloy, the results on the graph showed that there is a good improvement in damping characteristics due to adding ceramic and syn- 

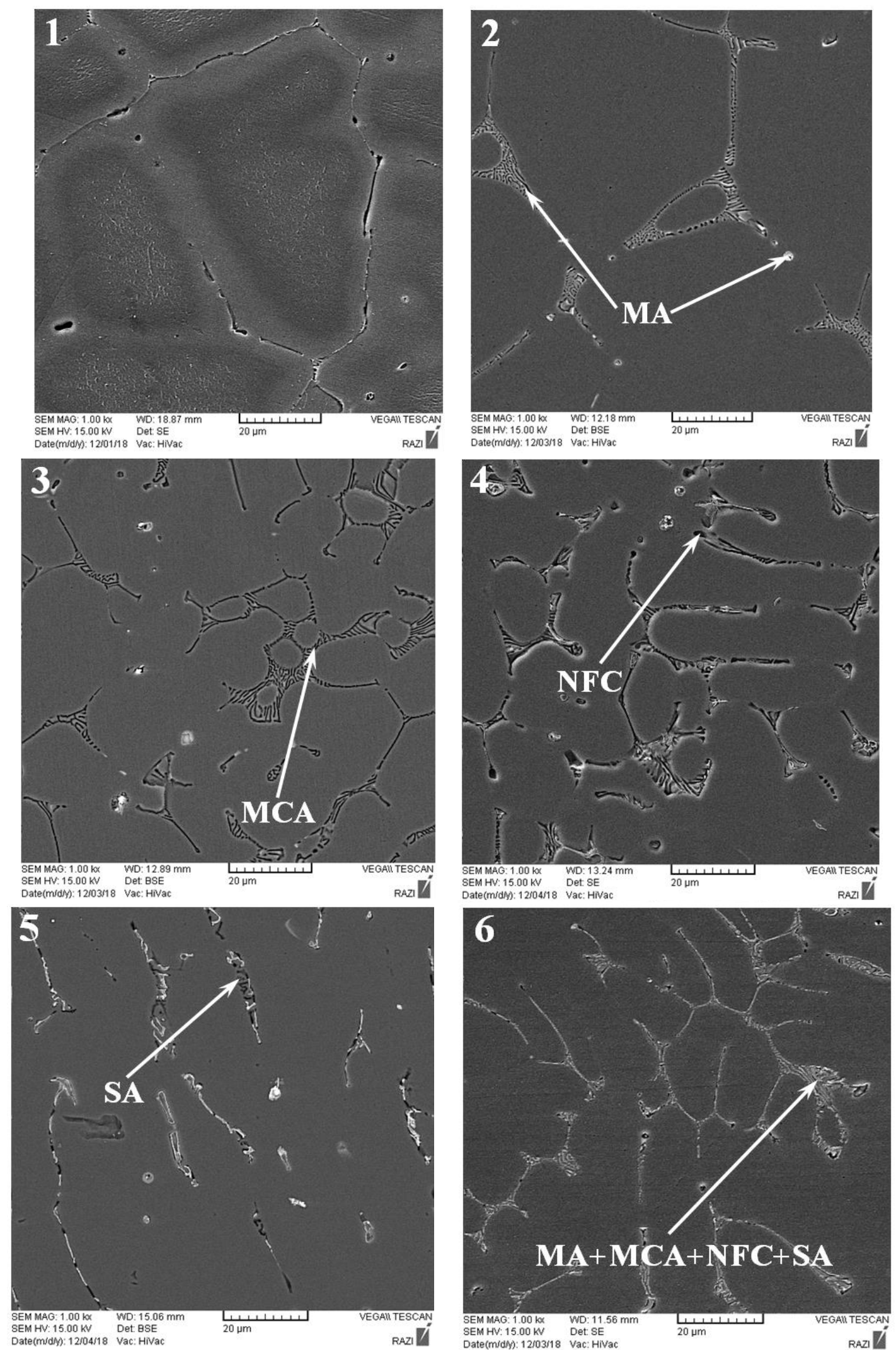

Figure 16: Represented photomicrography of scanning electron microscope of all test samples. 
thetic compared to Al 6063 alloy. Figure 14b also presented two types of reinforcements such as ceramic called NFC and a waste vegetable called SA reinforcements compared to $\mathrm{Al} 6063$ alloy, the results also show a good improvement in damping characteristics especially by adding NFC reinforcement, but for vegetable reinforcement, the rate of improvement of damping characteristic is low but not very bad. Figure $14 \mathrm{c}$ shows mixing of all types of reinforcements such as MA, MCA, NFC, and SA, as mentioned in samples 9. This mixing makes a good improvement of damping characteristics, but the peak value of acceleration happens at second sine wave and its recorded about $108 \mathrm{~m} / \mathrm{s}^{2}$, this change of peak value of acceleration due to change of natural frequency of adding all types of reinforcements together in one sample with the $\mathrm{Al} 6063$ alloy.

\subsection{Evaluation of wear loss test}

Wear is one of the important test cases of composite material. TQ-Plint TE91/1 Tribometer tested the wear characteristic test behavior of this work. A load of $10 \mathrm{~N}$ used for a time duration of $75 \mathrm{~min}$ at a constant speed of $200 \mathrm{rpm}$.

From the above results, there are many variations in the rate of types of composites during the experiments such as ceramics, synthetic, and vegetable reinforcements. Figure 15 shows the behavior in the wear loss with the effect of rate of $\mathrm{Al} 6063$ metal matrix composites and base Al 6063 alloy. When we see the results in Figure 15, it observed big difference between the base metal Al 6063 alloy and $\mathrm{Al} 6063$ metal matrix composites, which presents that the composites have a good change in the rate of wear characteristic resistance compared to base $\mathrm{Al} 6063$ alloy. The spread in the wear loss rate of the composites is better estimated from Figure 15. In this Figure, it observed that the wear loss rate of the composite with 5\% NFC sample 4 was averagely lower than all types of composites, this in dicates that $5 \%$ of NFC reinforced has good resistance to high temperature and friction and followed by sample 6 . But the less resistance to wear loss rate is sample 4 after the base Al 6063 alloy. The reason has come back to it's the weak shape of grain size of 5\% MCA and mixed with inclusions as shown in Figure 16(4) and lousy interaction of this reinforced synthetic with the base metal together.

\subsection{Microstructural evaluation}

A scanning electron microscope (SEM) was used to show photographically and studies the distribution analysis of
Al 6063 alloy and all four types of reinforced metals in the aluminum matrix as in Figure 16.

The microstructure analysis in Figure 16, shows the presence of equiaxed grains which attributed to the effect of stirring action which breaks the dendrite shaped structure and leaves the structure in the equiaxed form with fine intermetallic precipitates which seen in the matrix of Al. The investigation of the composite material of this work was made by the high precision technique process to cast suitable microstructure of the matrix with homogeneous particles distribution. The electron imaging of all the composites and the appearance of chemical homogeneities such as reinforcement/matrix interface with fewer inclusions make proper distribution of MMCs. The reinforced particles used in the present study have a good mixing, gathering, and bonding through grains to build a strong quantify uniform boundary particles distribution. This strong particles boundaries cause a huge place inside the aluminum matrix.

The particle distribution in cast composites may become inhomogeneous even when a homogeneous state of suspension maintained in the slurry. Pouring the solidification of liquid matrix alloy containing dispersed second phase particles, the particle in the melt can migrate towards or away from freezing front, and a particle near freezing front will either be rejected or engulfed. These two phenomena lead to the redistribution of the particles during solidification. These means the solidification cell size, and hence, the solidification rate influences the distribution of the reinforcement particle in the final ingot finally equiaxed grains absence in the ingot [24].

\section{Conclusions}

In this study, $\mathrm{Al} 6063$ alloy based composite reinforced particles are fabricated using two steps of techniques of the stir casting process. Details of the experimental investigation presented for the effects of different types of metal matrix composites on average surface roughness, chip shape formation style, mechanical properties, wear loss rate, damping characteristics properties and microstructural observation. The conclusions of the results in this investigation study can be summarized in the following points:

1. The surface roughness is significantly affected by the MA, MCA, NFC, and SA. Average surface roughness is more decreased by adding NFC and MCA nanoparticles. 
2. All four types of reinforced metals do not increase the average chip length. NFC was increasing average chip length while cutting speed of $10 \mathrm{~m} / \mathrm{min}$, but within cutting speed of $90 \mathrm{~m} / \mathrm{min}$, MA has a vital role in changing the length and formation style of the chip from discontinuous chip to continuous chip.

3. The stress-strain curves display that the YTS and UTS increase while the elongation decreases with increasing reinforcement content quantity.

4. The hardness of the MMCs is higher than $\mathrm{Al} 6063 \mathrm{al}-$ loy and the cast of MA composite increasing hardness more than the other types of MMCs due to the weight fraction of $\mathrm{Al}_{2} \mathrm{O}_{3}$.

5. Experimental results show that the impact strength increased by more than one reinforced metal, MA, NFC, and MCA play an essential role together for increasing the impact strength, but SA has a little effect increasing the impact strength.

6. The YTS and UTS which obtained from the results of MMCs are much more than $\mathrm{Al} 6063$ alloy, especially when adding all four types of reinforcement together. The effect of NFC for increasing YTS and UTS is small compared with other types of reinforced metals.

7. Elongation decreases approximately in the range of (30 to $60 \%$ ) compared with that of Al 6063 alloy under optimum constant values of reinforced metals. The smaller decrease of elongation was by NFC and MCA.

8. The damping characteristics improved dramatically by adding MA and NFC, and the analysis of the results showed that the damping characteristic was flimsy for SA reinforcement compared to other reinforcements.

9. MA exhibit low peak resistance values among all reinforced particles considered in this paper. The damping behavior of MA was found to be very good, even mixing with NFC, MCA, and SA.

10. It was evident that the NFC is giving high resistances to wear loss followed by MA and MCA but for mixing all types of reinforcements giving good improvement results in wear loss.

11. Microstructural evaluation by stir casting technique produces compact grain boundary, smaller, stronger, and uniform distribution grain size with good interface bonding of particulate matrix.

Acknowledgement: This work is a part of $\mathrm{Ph}$. D. thesis and mainly supported by the Department of Mechanical \& Mechatronics Engineering, College of Engineering, Salahaddin University-Erbil, Ministry of Higher Education and Scientific Research, Kurdistan Regional Government (KRG), Iraq.

\section{References}

[1] G. G. Sozhamannan, S. Balasivanandh, and V. S. K. Venkatagalapath, J. Sur. Eng. Mater. Adv. Tech, 2 (2012) 11-15.

[2] A. Kumar, S. Lal, and S. Kumar, J. of Mater. Res. Tech., 2 (2013) 250-254.

[3] K. K Alaneme and M. O. Bodunrin, Proceedings of the ATCA Tech. Corr.-Bull. Eng., Romania, (2013), pp. 105-110.

[4] V. K. Patel, B. Goyal, C. Shah, Proceedings of the Int. Conf. Multi. Res. Pract, INDIA. (2014), pp. 394-399.

[5] A. Canakci, S. Ozashin, and T. Varol, Arab. J. Sci. Eng. 39 (2014) 6351-6361.

[6] I. A. Alkadir, L. S. Salim, Eng. Tech. j., 35 (2017) 301-310.

[7] N. Aniban, R. M. Pillai, and B. C. Pai, Mater. Des., 23 (2002) 553556.

[8] S. Tzamtzis, N. S. Barker, N. H. Babu, J. Patel, B. K. Dhindaw, and Z. Fan, Compo. P. A-App. Sci. Man., 40 (2009) 144-151.

[9] M. Kathiresan, R. Theerkkatharisanan, and A. V. Rajan, Int. Res. J. Eng. Tech., 4 (2017) 569-574.

[10] J. Lakshmipathy and B. Kulendran, Trib. Indus. 36 (2014) 117-126

[11] R. G. Bhadare and P. M. Sonawane, Int. J. Eng. Adv. Tech., 3 (2013) 61-65.

[12] A. Ashofteh, M. Mosavi Mashhadi, A. Amadeh, Cer.-Sili., 62 (2018) 200-209.

[13] N. Saheb and M. S. Khan, Sci.of Sint., 50 (2018) 1-14.

[14] D. S. Prasad, C. Shoba, and K. R. Varma, Eng. Sci. and Tech. Int. J., 18 (2015) 647-679.

[15] M. O. Bodunrin, K. K. Alaneme, and L. H. Chown, J. Mater. Res., 4 (2015) 434-445.

[16] P. K. Sood, R. Sehgal, and K. Dwivedi, Ind. Acad. Sci. 42 (2017) 365-378.

[17] J. Hindi, U. A. Kini, S. S. Sharma, B. M. Gurumurthy, and M. C. G. Shankar, Proceedings of the 5th Int. Conf. Automo. Mechanical and Materials Engineering, Indonesia, (2015), pp. 69-73.

[18] Phanibhubshana V., C. Chandrappa, and H. Niranjan, J. Multi. Eng. Sci. Tech., 2 (2015) 255-260.

[19] K. K. Alaneme, M. O. Bodunrin, and A. A. Awe, J. King Saud Univ.Eng. Sci. 1 (2016) 1-8.

[20] K. Haider, M. A. Alam, A. Redhewal, and V. Saxen, Int. J. Eng. Res. Tech., 5 (9) (2015) 63-69.

[21] S. S. Raju, G. S. Rao, and M. M. Rao, Int. J. of Conce. Mech. Civ. Eng., 3 (2015) 17-21.

[22] S. B. Salem, E. Bayraktar, M. Boujelbene, D. Katundi, J. of Achiev. Mat. Man. Eng., 1 (2012) 7-17.

[23] S. A. Sajjadi, H. R. Ezatpour, M. T. Parizi, Mat. Des., 34 (2012) 106-111.

[24] J. Hashim, L. Looney, M. S. J. Hashmi, J. of Mat. Proc. Tech. 93 (1999) 1-7. 